\title{
The Emergence of Mathematical Modeling Competencies: An Investigation of Prospective Secondary Mathematics Teachers
}

\begin{abstract}
A study with prospective teachers without prior mathematical modeling experience sheds light on how their newly developed conceptual understanding of modeling manifested itself in their work on the final task of a modeling module within a pedagogy course in secondary mathematics curriculum and assessment. The main purpose of the module was to provide opportunity for the prospective teachers to experience the Common Core Mathematical Practice Model with Mathematics and begin to develop competency in modeling. Their work and reflections displayed a range of proficiency in several competencies associated with the modeling process. Examples of their work illustrating these ranges are provided. The prospective teachers expressed both struggle and rewards during the process, and reflected on challenges for teaching modeling. The results suggest that infusing modules in existing courses can be an effective way to elevate prospective teachers from unfamiliarity with modeling to noticeable levels of proficiency in various modeling sub-competencies.
\end{abstract}

\section{Introduction}

This article reports findings from a study with prospective teachers in the Southwest United States on the development of mathematical modeling proficiency. The main objective was to determine the effectiveness of a set of activities, organized as a module within a seniorlevel course in a teacher preparation program, in fostering the type of mathematical thinking demanded by modeling. To achieve this, we set out to uncover how the prospective teachers' conceptual understanding of modeling manifested itself in their work throughout the module on 
mathematical modeling whose final activity was the Tree Leaf task, an authentic mathematical modeling task originating from research in botany. In agreement with the literature (Blum \& Leiß 2006; Borromeo Ferri 2006; CCSSI 2010; Garfunkel \& Montgomery 2016), we described mathematical modeling as a process in which students consider and make sense of an everyday situation that will be analyzed using mathematics for the purpose of understanding, explaining or predicting something. This article focuses on the way prospective teachers with no modeling experience prior to the module navigated the modeling process while working on the Tree Leaf task, and the choices they made along the way, including how the realistic situation described in the task was simplified, the mathematical structures they selected for their models, and the competencies they exhibited in the process.

The project was guided by our interest in developing effective ways to incorporate mathematical modeling in teacher preparation programs, including those that do not require specific modeling courses. This is a critical issue since teachers cannot rely entirely on textbooks, where most of the tasks are intended to engage the modelers in using a given model and performing operations but not in developing their own model for given situations or validating conclusions (Meyer 2015). Thus, teacher preparation programs must develop modeling proficiency in prospective teachers so that they may have a critical view of the published curricula that will be handed to them.

The research questions addressed in this study were the following:

1. How did prospective teachers engage with the mathematical modeling process as they worked on the Tree Leaf modeling task?

2. How were modeling competencies displayed in the work by the prospective teachers? 


\section{What perspectives did the prospective teachers develop for teaching and learning}

mathematical modeling?

There are valuable reasons for focusing on mathematical modeling (Blum \& Niss 1991). Stillman, Kaiser, Blum and Brown (2013) argue that "applications and modelling and their learning and teaching in school and university have become a prominent topic in the last decades in view of the growing worldwide relevance of the usage of mathematics in science, technology and everyday life" (p.v). In current secondary education curricula, modeling tasks can be used as a way to promote students' conceptual understanding and the processes they develop during their efforts to solve a real-world problem (Lesh \& Doerr 2003). Additionally, because modeling tasks can be approached with different types of mathematics, the tasks require creativity and often connect a variety of content and practice standards within a single lesson, making it possible for students to experience the interconnectedness of mathematics concepts. The National Council of Teachers of Mathematics (NCTM) (2000) emphasizes the importance of representing physical, social, and mathematical phenomena through modeling. This can be accomplished in the classroom partly through the use of mathematical modeling tasks, as required by the Common Core State Standards in Mathematics (CCSSM) in the United States. CCSSM include the standard for Mathematical Practice Model with Mathematics and also the conceptual category for high school students Mathematical Modeling (CCSSI 2010). Additionally, there have been multiple recommendations issued recently to incorporate mathematical modeling in teacher preparation programs, including the GAIMME report (Garfunkel \& Montgomery 2016), the Standards for Preparing Teachers of Mathematics (Association of Mathematics Teacher Educators 2017), the NCTM (2016) Annual Perspectives in Mathematics Education publication, and the Mathematical Education of Teachers II report 
(Conference Board of the Mathematical Sciences 2012). A comprehensive understanding of the strategies and procedures that prospective teachers use to create a mathematical model for a complex open-ended task and the modeling competencies they develop will provide valuable insight into effective ways of preparing future and current teachers to teach mathematical modeling.

\section{Theoretical Perspectives}

Research in mathematical modeling in mathematics teacher preparation is expanding to include the learning of modeling for prospective teachers as students of mathematics and to include perceptions about teaching mathematical modeling in the secondary grades (Anhalt \& Cortez 2016; Anhalt, Staats, Cortez \& Civil, in press; Doerr 2007; Lingefjärd 2002). Here we review relevant work on mathematical modeling, including the process, teacher preparation, and a theoretical framework by Maа $\beta$ (2006) that captures the development of mathematical modeling through a set of sub-competencies that are activated during modeling work and that cumulatively build competency in modeling. In addition, we make observations on the prospective teachers' modeling work, on the use of Mathematical Practices as characterized in the Common Core (CCSSI 2010) and their experiences through productive struggle as defined by the NCTM (2014).

\section{Mathematical Modeling as a Process}

During modeling activities, students interpret, describe, explain, justify, reject or revise models (English 2003). As necessary, to reduce its complexity, students simplify the realistic situation by making justified assumptions and by identifying those variables they consider essential, leading to an idealized version of the reality (Mooney \& Swift 1999; Blum \& Leiß 2006; Kaiser \& Schwarz 2006; Kaiser \& Stender 2013). The simplified reality, sometimes called 
the real model (Blum \& Leiß 2006; Borromeo Ferri 2006), is translated into mathematics using equations, numeric tables, graphs or other appropriate representations constituting a model. The solution of the model is usually a problem-solving step leading to a mathematical answer that must be interpreted in the context of the original situation. The conclusions from this process and their implications may be perfectly adequate for the stated purpose or may need to be improved based on the accuracy needed in the answer, reasonableness of the conclusions, or some other factors. In this case, the original choices must be revised in order to follow a similar procedure to create an improved model that leads to better conclusions (Bender 2000; Dym 2004; Garfunkel \& Montgomery eds. 2016). The diagram representing this process that was shared with the prospective teachers is shown in Figure 1. It is based on the CCSSM cycle diagram but modified by the authors in two ways. First, the descriptor of each box was expanded to make it more meaningful (e.g. using "Interpret solution and draw conclusions" instead of the single word "Interpret"). Second, the box "Create a simplified situation" was added to represent the development of a real model, which is not explicitly depicted in the CCSSM cycle but has sub-competencies associated with it (see Table 1). In practice, the modeler may move back and forth between two stages, be involved in activities related to two different stages simultaneously, back up and restart part of the process, etc. (Lingefjärd 2002). These instances are not depicted in the diagram.

\section{Prospective Teacher Education in Mathematical Modeling}

Research in mathematics teacher preparation largely points to limited opportunities to experience mathematical modeling. Regarding understanding of the modeling process, Siller and Kuntze (2011) found $43.6 \%$ of prospective teachers in their study did not answer a question about describing phases of the modeling process and that some of those who answered this 
question "did not describe all phases" (p.37). Ng (2013) found that prospective teachers displayed difficulties getting started on an open-ended task used in a study. These results are possibly due to insufficient exposure to mathematical modeling or to the kind of thinking required for mathematical modeling in their own mathematics education. This indicates a need to make mathematical modeling an integral part of teacher education programs as recommended by the Mathematical Education of Teachers II report (Conference Board of the Mathematical Sciences 2012). In a case study reported by Soon and Cheng (2013), prospective teachers in Singapore with no prior modeling experience expressed concerns about their lack of understanding in teaching mathematical modeling which is currently being introduced into the curriculum. Further, there is a need in teacher preparation globally to provide opportunities for participation in and reflection on mathematical modeling in terms of teaching and learning (Anhalt \& Cortez 2016; Doerr 2007; Ng 2013; Siller \& Kuntze 2011). Prospective teacher participation in mathematical modeling activities helps form an understanding of the nonlinear cyclic nature of the process and its connection to the thinking required to develop models (Doerr 2007). Additionally, the Standards for Preparing Teachers of Mathematics (Association of Mathematics Teacher Educators 2017), an imminent influential report, advocates for mathematical modeling as an integral component in teacher preparation programs at the K-12 grade levels.

In a study with undergraduate prospective mathematics teachers, Anhalt and Cortez (2015) found that prospective teachers reported engaging with particular Common Core Standards for Mathematical Practices while working on modeling tasks. In particular, the prospective teachers reported engaging in Mathematical Practice 1 (Make sense of problems and 
persevere in solving them), Mathematical Practice 2 (Reason abstractly and quantitatively), and Mathematical Practice 6 (Attend to precision) in their solutions.

\section{Competencies in Mathematical Modeling}

We adopt the viewpoint of mathematical modeling as a process for which competency must be developed. Several definitions of modeling competency have been presented that define the ability to perform the processes involved in modeling (Frejd 2014; Kaiser \& Brand 2015; Niss, Blum \& Galbraith 2007). Most relevant to our work are the definitions by Maa $\beta$ (2006) and by Blomhøj \& Jensen (2003). Blomhøj and Jensen (2003) define mathematical modeling competency as "being able to autonomously and insightfully carry through all parts of a mathematical modelling process in a certain context" (p.126) and Maa $\beta$ writes that "Modelling [sub-]competencies include skills and abilities to perform modelling processes appropriately and goal-oriented as well as the willingness to put these into action" (p.117). The skills and abilities referred to are summarized in Table 1 . These definitions imply that modeling competency is tied to the specific description of the modeling process, such as the diagram in Figure 1; and that mathematical modeling competency is characterized by readiness for action (Jensen 2007). A comprehensive account on various descriptions of modeling sub-competencies is given by Kaiser and Brand (2015).

Niss and Jensen (2011) explain that sub-competencies are manifested in mathematical activities, such as the development of mathematical models, and suggest that someone's possession of a sub-competency can be assessed using a three-dimensional approach. The dimensions are degree of coverage, radius of action, and technical level (Niss \& Jensen 2011; Jensen 2007). With respect to modeling competency, degree of coverage refers to the extent to which a person masters those aspects that characterize modeling; the radius of action is the 
spectrum of contexts and situations (intra- and extra-mathematical) in which the person can activate the competency; and technical level refers to how conceptually and technically advanced the tools are that can activate the competency (Niss \& Jensen 2011).

In our study we will only focus on the degree of coverage based on a finer-grain framework by Maaß (2006), who breaks up the modeling competency into five categories that closely mirror the stages of the modeling cycle. Each category contains a list of subcompetencies that are sufficiently general to apply to most modeling diagrams, including the one shown in Figure 1. We concentrate here on four of the sub-competencies listed by Maa $\beta$ (2006) that are underlined in Table 1: (1) making assumptions for the problem and simplifying the situation; (2) mathematizing the relevant quantities and their relations; (3) interpreting mathematical results in extra-mathematical contexts (which we refer to as contextualizing); and (4) reflecting on other ways of solving the problem or if solutions can be developed differently. Since the list of sub-competencies described by Maа $\beta$ (2006) does not involve the level of proficiency in competencies associated with the modeling process, we discuss prospective teachers' displayed proficiency based on Niss and Jensen's notion of degree of coverage (2011). Mathematicians who use modeling in their research activate these sub-competencies and are comfortable starting with assumptions associated with a highly simplified situation and moving toward a more realistic one iteratively as discussed in the Guidelines for Assessment and Instruction in Mathematical Modeling Education (GAIMME) report (Garfunkel \& Montgomery 2016). Reflecting on alternate solution approaches is a useful way to improve a model through iterations of the process.

\section{The Role of Mathematical Practices in Mathematical Modeling}


The eight Mathematical Practices from the Common Core (CCSSI 2010) can take on a visible and important role in examining mathematical modeling work. Besides Mathematical Practice 4 (Model with mathematics), some standards for mathematical practice, called for in modeling (Anhalt \& Cortez 2016), are intimately related to modeling competencies. For example, Mathematical Practice 2 (Reason abstractly and quantitatively) includes "the ability to decontextualize - to abstract a given situation and represent it symbolically and manipulate the representing symbols... - and the ability to contextualize, to pause as needed during the manipulation process in order to probe into the referents for the symbols involved" (CCSSI 2010, p. 6). In relation to modeling, these can be interpreted as essentially equivalent to the competency categories of setting up a mathematical model from the real model and interpreting mathematical results in a real situation (Maaß 2006, p.116). Mathematical Practice 5 (Use appropriate tools strategically) involves considering "the available tools when solving a mathematical problem" and making "sound decisions about when each of these tools might be helpful" (CCSSI 2010, p. 7). Other Mathematical Practices are connected to modeling. For instance, the early stages of the modeling process require analysis of the situation and sense making so that essential variables can be identified. Later, the validation stage often leads to revision of the model, modification of the assumptions or even starting the process over. These elements of the modeling process are clearly aligned with Mathematical Practice 1 (Make sense of problems and persevere in solving them).

\section{Productive Struggle in Mathematical Modeling}

In general, modeling problems have more than one entry point and they require initial choices that lead to various possible solution approaches. If a modeling task has multiple acceptable solutions that cannot be judged as right or wrong, the modeler must decide if the 
solution is sufficiently adequate for the purposes of the task. It is possible that students with a conception of mathematics problems as having a unique correct answer would experience cognitive dissonance (Festinger 1962; Stillman, Brown \& Galbraith 2013), which develops when the learner perceives conflict in what they know and what they are experiencing; thereby leading to disequilibrium in cognition, or frustration. In a study on the initial modeling experience of teachers, $\mathrm{Ng}$ (2013) finds that "there were feelings of frustration and loss in a few pre-service teachers who were used to more routine mathematical tasks as they were not aware that time spent on decision making to select the variables to focus upon and to discuss how to move on from the data working towards the goal was a necessary part of the modelling process" (p. 345). For teachers, cognitive dissonance and reflection on student experiences can help them resolve the conflicts and reconsider their notions about teaching and learning mathematics (Olson, Colasanti \& Trujillo 2006).

The expressed frustration can be viewed as productive struggle. Hiebert and Grouws (2007) describe this type of struggle to mean expending "effort to make sense of mathematics, to figure something out that is not immediately apparent” (p. 387). NCTM (2014) advocates for supporting students in struggling productively by viewing "struggles as opportunities for delving deeply into understanding the mathematical structure of problems and relationships among mathematical ideas, instead of simply seeking correct solutions" (p. 48). In our study, we sought to capture both the productive struggles of the prospective teachers' learning experiences and their insights on teaching mathematical modeling.

\section{Research Design}

This study explores the emergence of certain modeling competencies that prospective secondary mathematics teachers learned to activate by the end of a module organized as eight 
75-minute class periods within a senior level curriculum and assessment mathematics pedagogy course prior to the student teaching semester.

The module was designed to foster the type of mathematical thinking demanded by modeling. Initially, the module focused on two concepts: (1) the notion of decontextualization as the translation of a situation given in any context into mathematical language, emphasizing assumption making as part of the process; and (2) the practice of exploring alternate solution approaches within a problem, which is useful as part of the validation stage of the modeling process. Throughout this period, the prospective teachers worked on problems, not all modeling tasks, specifically selected for the purposes of identifying implicit assumptions made in the solution or explicit assumptions needed for a particular approach, and for proposing alternate solution approaches. This part of the module concluded with an in-depth presentation and unpacking of the modeling process. Several modeling tasks were introduced in the remainder of the module as open-ended tasks. For each task the preservice teachers were asked to submit written reflections on their navigation through the modeling process, to communicate solutions and report the assumptions that impacted their models. Results from the implementation of another modeling task from this module about a lost cell phone are reported in Anhalt and Cortez (2016).

The prospective teachers had prior experience with the Common Core Standards for Mathematical Practices from a previous pedagogy course but they did not have experience doing mathematical modeling or reflecting on the role that other mathematical practices play in the modeling process. Our module provided this experience.

Prior to the module, we distributed a pre-questionnaire that surveyed the prospective teachers' past experience in mathematical modeling in their k-12 and undergraduate mathematics 
education. Their responses revealed that none had prior experience with modeling in mathematics, except for one student who was simultaneously enrolled in a modeling course at the university.

The focus of this paper is on the work of the prospective teachers on the Tree Leaf task as a mathematical activity where modeling competency manifests itself. The Tree Leaf task (see Figure 2) spanned the final two class periods of the module plus an additional week when the prospective teachers worked on the task and prepared their final presentations.

\section{The Tree Leaf Modeling Task}

English (2009) expressed that we need to "engage students in authentic problem solving involving complex systems within an interdisciplinary context" (p. 161). The Tree Leaf task was inspired from data found in a scientific article in the American Journal of Botany (Alexandra, Holbrook, \& Ewel 2004) and is about the decrease in leaf size on a particular type of tree as the tree ages and its ability to produce oxygen during photosynthesis changes. Field measurements tracked leaf growth of trees ages 1,3, and 11 years. The goal of that study was to determine if there was a developmental basis or functional consequences of the leaf size variation. The modeling task we created gave background information, provided data taken directly from the botany article, and asked the prospective teachers to create a mathematical model that was consistent with the article data and could predict the leaf size variation of trees of ages 4-10, which were not tracked in the field study. This is an example of what mathematicians would do to complement the field study with modeling.

The is a rich task as it requires simplification, background research, making assumptions, formulating a model, interpreting and validating the results with multiple opportunities for iterations of the modeling process. The prospective teachers were expected to go through a full 
modeling cycle and possibly several iterations. They were encouraged to work in small groups and talk with each other outside of class in order to deepen their understanding of the context and make sense of the problem. Nevertheless, they were required to develop individual models and reports containing their assumptions, their model, and a contextual interpretation and validation of their results. They concluded their individual reports with reflections on their experiences as learners of mathematical modeling, their uses of the Mathematical Practices, and their insights on teaching mathematical modeling.

\section{Setting, Participants, and Data Sources}

The study participants were eleven undergraduate prospective teachers in a secondary mathematics teacher preparation program within the Mathematics Department of a large, public university in the United States. The prospective teachers worked on the module tasks in rotating groups of three and four, collaborating in the formulation of models, and giving presentations to the other groups describing their work and justifying their choices. The reflections on their work and on teaching and learning mathematical modeling served as a window to their modeling competency and insights as future teachers. The reports, posters and presentations served as data sources to inform this study.

\section{Data Analysis}

We assigned pseudonyms to the 11 prospective teachers to secure their identities and to be able to report comments from their reports. We analyzed their individual reports in several broad areas: their journey through the mathematical modeling process, their use of Common Core Mathematical Practices, their productive struggle in modeling, and their perspectives on teaching mathematical modeling. 
The mathematical modeling process. We separately and systematically coded the prospective teachers' reports by each sub-competency within the mathematical modeling process underlined in Table 1. Evidence of the four sub-competencies was identified in each of the prospective teachers' reports and agreed upon by the researchers. We discuss the specific analysis for the four sub-competencies below.

Assumptions and situation simplification. The assumptions and choices identified in a report were used to classify the level of simplification of the situation into Most Simplified, Moderately Simplified and Least Simplified. We defined Most Simplified as (a) assuming leaf size decreases linearly in time; or (b) approximating only the mature leaf dimensions and excluding factors about the number of leaves in the trees or how oxygen relates to leaf size. Least Simplified includes at least two of the following: (a) accounting for leaf size since budding and not only after leaves mature; (b) accounting for the number of leaves in trees; and (c) accounting for leaf oxygen production. Moderately Simplified is in between least and most.

Formulation of models. We sought to classify the type of model the prospective teachers formulated. Since the Tree Leaf task can be approached in different ways, we looked for models based on functions used to approximate the data and for models based on other mathematical structures such as averaging methods to interpolate data. When functions were used, we categorized the models by the type of function selected. Further, we expected that the prospective teachers would include geometric ways to represent the area of the leaves so we coded based on how the leaf area was modeled based on their shape and their length.

Contextualization. We classified the contextualization of their model results as high level or low level of proficiency displayed. A low level of proficiency in contextualization refers to limiting the interpretation of the mathematical results to a description of the model or its 
variables with little connection to the situation context and without discussing the implications of the results. We coded one prospective teacher's contextualization as incomprehensible. A high level of proficiency in contextualization discusses connection to the situation context and the implications of the results on the original problem. Example cases are displayed in Figure 3.

Alternate solution approaches. We asked the prospective teachers to reflect on other ways to model the situation besides the approach that resulted in their final mathematical models. From a research perspective, our aim was to elicit thoughts on other ways that the prospective teachers could think about solving the modeling task. We coded their reports based on whether they considered modifying their assumptions or if they offered alternate mathematical approaches or different types of functions that could approximate the data in the problem.

Mathematical Practices. A goal of the course in which the module was implemented is for the prospective teachers to become fluent in planning instruction that positions the teacher as facilitator of the Common Core Mathematical Practices. They were asked to reflect on which of the Mathematical Practices they engaged with during their work on the Tree Leaf Task. The prospective teacher reports listed the Mathematical Practices they claimed to have used. We coded for evidence that substantiated their claims, compared the reasoning for our coding, refined our criteria and reached a coding consensus. We only considered those Mathematical Practices supported by evidence.

Productive Struggle. As part of the written reflections of their own learning experiences throughout the modeling module, the prospective teachers were asked to discuss particular challenges and successes they experienced while engaged in the culminating modeling task. This portion of their reflection provided a space for the students to share openly about the difficulty level of the task in association with their frustrations, perseverance, and rewards after 
spending an appropriate amount of time on the task. In coding for productive struggle, we looked for language associated with frustrating or rewarding experiences that this task instigated, whether it was implicit or explicit. Only narratives of frustrations or rewards directly connected to their work in modeling were considered. Instances of expressed emotion were recorded and categorized as rewards or frustrations. The frustrations category included instances of expressed struggle that led to frustration, while the rewards category included instances of the use of the word reward or instances alluding to gaining new insight.

Teaching Modeling. Finally, we examined the prospective teachers' reflections on teaching and learning mathematical modeling, and highlighted themes that emerged from the data. For this particular area of analysis, we designed the open-ended prompt, "What insights have you developed as a result of modeling this problem and reflecting on the teaching and learning of mathematical modeling?" The goal was to have prospective teachers reflect on what they thought was important for teaching mathematical modeling in secondary schools. For this portion of the data, we drew approaches from grounded theory method by Strauss and Corbin (1990), which allowed coding the prospective teachers reflections on teaching and student learning through the lens of emerging themes. This was of particularly high interest to the research since the open-ended nature of the prompt allowed for a wide range of ideas for teaching mathematical modeling. The common themes among the prospective teachers' reflections were identified by the researchers independently and then a comparison was drawn among the identification to reach a consensus of the common relevant themes for teaching and learning modeling.

\section{Findings}


We report on the modeling sub-competencies revealed by the data analysis, focusing on the four sub-competencies from Maaß's framework that are underlined in Table 1. We then report on the prospective teachers' use of Mathematical Practices during their engagement with the task, their productive struggle, and their reflections on their future teaching of mathematical modeling followed by student learning.

\section{The Mathematical Modeling Process}

Assumptions and situation simplification. In stating assumptions, seven of the 11 prospective teachers explicitly mentioned that the leaf surface areas could be approximated by areas of common geometric shapes. All prospective teachers assumed facts about the tree growth, sizes of budding and mature leaves, and the number of leaves per tree. In addition, all prospective teachers identified a type of function that can fit the given data.

A theme that emerged in their reflections was the way they introduced assumptions. Specifically, eight prospective teachers wrote or implied that they introduced assumptions at various stages of the modeling process and not only in the early stages. The other three prospective teachers did not mention when they made assumptions. Based on reported descriptions of the modeling cycle, one might think that assumptions are made early in the process when the model is being developed (or revised). However, the prospective teacher reflections show that some assumptions are being made during other stages also, as depicted in Figure 1. Lauren wrote "I assumed that all trees in this model were receiving the same sunlight ... As I continued on in the problem I began to make more assumptions." And Alejandro wrote during the validation stage that "The reason that it is valid to utilize this type of model is that we know that years 1, 3, and 11 all follow a logistic growth model and so we can assume that so does years 4-10." 
A second theme that emerged in the analysis of the reflections was that an assumption stated explicitly was somewhat different and more restrictive than the assumption used, and needed, in the model. In the task, an estimate of the leaf areas was needed, so a common assumption made by the prospective teachers was that the area of a leaf was approximately equal to the area of a common geometric shape with specified dimensions related to the leaf length. Four of the eleven prospective teachers, however, stated assumptions like "[the] leaf is circular in shape with a radius about half the length" (David) or "as the leaf matures it takes the shape of a circle" (Alejandro) or "all trees have triangular leaves" (Bob). These are overstated assumptions since a leaf does not have to be circular for its area to be approximated by the area of a circle. Along the same lines, two prospective teachers listed the assumption that "leaves die after 87 days" rather than leaves stop growing after 87 days (David, Heidi).

The task asked the students to use the data provided to understand the ability of the trees to produce oxygen during photosynthesis as the trees get older, which is too complex to be analyzed through modeling without simplification. Our classification of the prospective teachers' level of simplification resulted in the distribution: Most simplified=3; Moderately simplified =5; and Least simplified=3. In the Most simplified situations (Cecilia, Logan and Heidi), the essential variables identified by these prospective teachers were the size of mature leaves and the tree age. Yet, the amount of oxygen release and the number of leaves per tree were assumed unimportant. Logan mentioned that oxygen production is "dependent on the size of the leaf" but never specified how. The three prospective teachers with a level of Least simplification (Casey, Jesus and Alejandro) considered the total number of leaves in the trees to be an essential variable. For example, Jesus assumed that the number of leaves was proportional to the volume of a cone and Casey assumed that the number was proportional to the volume of a 
sphere. Alejandro wrote that the "volume of leaves increases" as the tree gets older and considered leaf size since budding as a relevant variable in the simplified situation. Jesus and Casey considered oxygen production to be an essential variable and assumed it to be proportional to the total leaf area.

A prospective teacher alluded to the connection between the level of simplification used and the possible models that he was able to consider as a result. "I also found that I got incredibly frustrated when my model began to fall apart with attempting to find a function based on the particular day since budding" (Bob).

Overall, the type of assumptions made by the prospective teachers was closely connected to the degree to which they simplified the situation and determined key features of their models. For instance, assuming that all leaves are mature led the prospective teachers to use a different function for the length of the leaves than those who accounted for the size of budding leaves. However, some assumptions were made in order to simplify the mathematics in the model. For example Maribel's wrote "I assumed for simplicity that the rates were constant and took an average of the rates for each tree to be the overall rate ( $b$ value) for each equation."

Formulation of Models. The formulation of a mathematical model involves the process of decontextualizing the simplified situation, which Maa $\beta$ (2006) calls mathematizing relevant quantities and their relations. All 11 prospective teachers chose to approach this problem by fitting the data given in the task with a function and interpolating the leaf lengths to intermediate years. The ability of a tree to produce oxygen was assumed to be proportional to the leaf areas. This general approach combined the use of functions and proportionality with geometry within a single solution to the problem. These ideas were generated during a period of open collaboration when the prospective teachers brainstormed with one another. Since the reports were individual, 
however, the models also had differences. For example, the functions themselves were not all the same; four prospective teachers (Cecilia, Ahmed, Jesus, Heidi) used exponential functions, three (Lauren, Bob, Casey) used power functions, three (David, Alejandro, Maribel) used logistic functions, and one (Logan) used a linear function. We describe here three representative models developed by prospective teachers.

Model A: Exponential function. Jesus approximated the area of a leaf by the area inside a circle of radius $L(\mathrm{t}) / 2$, where $L(\mathrm{t})$ is the length of a leaf of a $t$ year old tree. He approximated the total number of leaves on a tree using the volume of a cone. The focus then was to find an expression for $L(\mathrm{t})$. Jesus assumed that all leaves were mature so that, based on the second figure of the task, he defined $L(1)=45, L(3)=29$ and $L(11)=14$. He chose to fit these data with the exponential function $L(t)=r^{t-p}+c$, which contains three unknown parameters, $r, p$ and $c$, so it is possible to make it go through all three points $(1,45),(3,29)$ and $(11,14)$. The result is $L(t)=2^{(11-t) / 2}+13$

Model B: Power function. Bob approximated the area of a leaf by the area of a triangle with base equal to $L(\mathrm{t})$ and height $4 / 3 L(\mathrm{t})$. To find an expression for $L(\mathrm{t})$, Bob also assumed that all leaves were mature so that $L(1)=45, L(3)=29$ and $L(11)=14$, as before. However, he chose to fit these data with the power function $L(t)=A t^{b}$.This formula contains only two unknown parameters, $A$ and $b$, so it is not possible to make it go through all three points $(1,45),(3,29)$ and $(11,14)$. The approximation used by Bob was $L(t)=45.224 t^{-0.451}$. Table 2 shows a comparison of the leaf length approximations using Models A and B.

Model C: Logistic function. Three prospective teachers chose to approximate the leaf length starting from budding up to maturity. The data is given graphically in the second figure of 
the task. In order to generate the S-shape curves starting from near zero length at day 1 and up to a maximum length at day 87 , the prospective teachers used a logistic function of the form $L(s)=$ $\frac{q}{1+a e^{-k s}}$, where $s$ is the age of the leaf in days. The constants $q, a$ and $k$ need to be determined for each year. For example, David used the function $L(s)=\frac{45}{1+180.3 e^{-0.125 s}}$ for 1-year old trees, $L(s)=\frac{30}{1+56.89 e^{-0.103 s}}$ for 3 -year old trees, and $L(s)=\frac{18.59}{1+27.76 e^{-0.054 s}}$ for 11-year old trees. Although the prospective teachers did not plot these functions, we plot them in Figure 4 to show that they are a good approximation to the data in the second figure of the task.

Contextualization. The prospective teachers were required to include in their reports a description of their models and a contextual interpretation of their results; that is, they had to address Maaß’s sub-competency of interpreting mathematical results in extra-mathematical contexts. Based on the contextualization proficiency displayed by the prospective teachers, four of the 11 prospective teachers displayed a low level of proficiency in interpreting the mathematical results in the context of the problem. Three of those limited their discussion to a description of what the variables in the mathematical model meant but did not discuss implications of the model results in context. The remaining seven displayed a high level of contextualization, which was characterized by implications derived from the features of the functions in their model solutions. For example, Ahmed wrote "From the graph of the solution, we can see that the tree produces the most oxygen when it is approximately nine and a half years old." Jesus wrote "Since this function is never negative, we have that the oxygen production is always positive and increasing." These comments are representative of the high-level contextualization. 
Alternate Solution Approaches. The assignment asked the prospective teachers to consider other ways to model the situation besides that approach they took. Six out of the 11 prospective teachers answered by suggesting ways to modify their assumptions in order to go beyond what they did. Three other prospective teachers mentioned alternate solution approaches based on what the others had discussed during discussions and work time among all of them. One prospective teacher mentioned the possible use of a cubic function (which nobody used) and different assumptions. Finally, one prospective teacher did not answer the question directly.

\section{Prospective Teachers' Use of Mathematical Practices}

The prospective teachers were asked which (if any) of the Common Core Mathematical Practices were experienced with this particular mathematical modeling task. Of the eight practices, three were chosen most often, including the obvious Mathematical Practice 4 (Model with mathematics), so we focus our results on Mathematical Practice 1 (Make sense of problems and persevere in solving them) and Mathematical Practice 5 (Use appropriate tools strategically).

The reports showed that six of the prospective teachers referenced Mathematical Practice 1 by explicitly using the word perseverance or persevering in their reflection, and another four implicitly referred to perseverance via phrases such as "I kept going" and "I started over." Nine of the 11 prospective teachers claimed to have used Mathematical Practice 5 (Use appropriate tools strategically), although their definitions of tools varied greatly. Five of these nine prospective teachers claimed the tools they used were technology-related, such as graphing calculators, software, and the desmos.com online site. Two of the nine defined their tools as the functions and graphs they used when working to find a solution. The remaining two prospective teachers listed "prior math knowledge" and mathematics textbooks as tools used.

\section{Productive Struggle: Frustrations and Rewards}


In their reports, the prospective teachers expressed emotions, categorized as frustration or rewards, in connection with the Tree Leaf modeling task. Instances of expressed emotion were recorded and categorized as rewards or frustrations. Six prospective teachers explained how the project was rewarding for them or listed insights they gained from the project. A salient theme that connected these rewards was an insight into the difference between mathematical modeling and traditional word problems. Jesus said, “...I have come to realize a stark difference between modeling problems and word problems. I now see that modeling problems... use multiple mathematical ideas in solving the problem, and require constant interpretation of results. Word problems are not like this because...there is usually very little interpretation of the answer." Addressing the versatility of the task, Alejandro stated,

The biggest insight I found in this problem is that these [modeling] problems can be so rich and rewarding....I think the biggest thing I have taken from this [project] is that I know that I can use one of these problems and address such a wide variety of standards and practices, which really makes the process rewarding.

Frustration among prospective teachers in mathematical modeling has been described previously. In our study, four prospective teachers expressed frustration stemming from the multiple attempts and iterations needed in the modeling cycle to find a function that fit the data adequately. Casey realized that the challenges of modeling problems will also affect her as a teacher, but she believes that they are worth the extra effort. "At first, I was very frustrated with this problem. ...I have realized that teaching modeling will be extremely difficult. ... I hope to include modeling in my classroom, even if it is only in small ways."

During their poster presentations, the prospective teachers shared the models they developed, the justification of the assumptions and the outcomes of their models. These 
presentations created a space for the prospective teachers to ask questions about each other's models and the results they yielded, and to make critical comparisons in terms of similarities and differences. During the discussion, the prospective teachers reiterated comments regarding their struggles getting started with the task, not knowing which assumptions to consider important, and unsure of how to interpret the data in the problem statement. They expressed frustration at various points during the process, for example, several of them could not decide how to compute the area of the tree leaves since the leaves are not regular polygons; others could not identify a function that fit the data.

\section{Reflections on Teaching and Learning Mathematical Modeling}

In order to examine prospective teachers' ideas for teaching mathematical modeling to their future students, we asked them to reflect on teaching modeling and share insights they developed after solving the Tree Leaf task at the conclusion of the module. The reflections revealed insights about the teaching and learning of mathematical modeling, from which four themes emerged: (a) the value of different approaches to formulate models; (b) the mathematical thinking and reasoning required for mathematical modeling; (c) challenges on teaching mathematical modeling, and, (d) assessment of mathematical modeling, which was addressed by a few prospective teachers.

The value of different approaches to formulate models. Seven of the 11 prospective teachers discussed the value of different approaches for formulating mathematical models and connected this to the open-ended nature of mathematical modeling. For example, David wrote, "The more variety in the student work, the more mathematical communication will be required for students to understand each other's work. Variation challenges students to understand different methods of solving the same problem and challenges them to critique the reasoning of 
others." And Maribel wrote, "I realized that there are going to be instances in teaching where students use different methods of solving a problem. We [future] teachers need to recognize equivalences in mathematical thinking that are used by students to interpret solutions to the same problem."

\section{The mathematical thinking and reasoning required for mathematical modeling.}

Seven of the 11 prospective teachers discussed how mathematical modeling promoted thinking and reasoning, and that mathematical conceptual ideas are an essential component of modeling. Below are sample comments made by the prospective teachers. Ahmed wrote, "This problem would be a great platform for explaining how to determine the regression of data... I can see the opportunity to teach problem solving skills while working within the curriculum through modeling." Alluding to students listening to each other's thinking, Bob wrote, "Mathematical modeling can be used to emphasize critiquing the reasoning of others; [it] makes it apparent whether or not students understand what they are doing when they are challenged to assess the validity of other students' thinking about a problem."

And finally, Maribel wrote about the importance of going through the thinking required for the Tree Leaf task,

I have learned how important the [... modeling] process is to mathematical thinking by doing this problem. This [... experience] allows us as [future] teachers to recognize that students ... [have] differences in reasoning ... One problem that engages students on multiple levels of mathematical exploration is more effective than having many lowengagement problems for students to do.

\section{Challenges on teaching mathematical modeling using the Tree Leaf task. Five}

prospective teachers felt that the task was difficult and discussed the notion that the difficulty 
would carry over to teaching mathematical modeling. For example, Bob wrote, "This problem would be too difficult for students in the current state of educational system. I have no idea how well this problem might go over in an environment where modeling problems are more commonplace.” And Lauren expressed,

Honestly, I think this problem might be too complicated for high school students ...but I think most high school students would probably work through this problem like I did. They would probably steer clear from two variable functions and try to simplify the function using one set of data.

Assessment of mathematical modeling. Eight of the 11 prospective teachers addressed the topic of assessment in mathematical modeling. All eight prospective teachers mentioned that assessment of student work in mathematical modeling should consider the process that students engage in when solving mathematical modeling problems. Of these eight, five discussed the value of various approaches in mathematical modeling. For example, Jesus asserted that, Mathematical modeling is great for assessing student ingenuity in math to solve problems, and because of the variability in approaches, assessment becomes more of an object of the students' assumptions, techniques, use of technology, justifications, and communication skills rather than the [accuracy] of the model; [that is,] assessment of the modeling process.

In addition, Maribel expressed,

I would assess openly; I would grade mathematical modeling based on effort and process of thought. I would be aware of different solutions and solution methods, and their ability to correlate the math used in the context of the problem. I want to see that 
students are using Mathematical Practices and creative thinking while solving and working through mathematical modeling problems.

\section{Discussion}

In this section we discuss our findings and their significance in relation to the research questions. Since none of the prospective teachers had been exposed to mathematical modeling prior to the course where the module was implemented, we can attribute any development and possession of modeling competency to participation in the module. Describing the degree of coverage a person has of a competency as the extent to which a person masters those aspects that characterize that competency (Niss \& Jensen 2011), we found that the prospective teachers' work reflected some degree of proficiency of the four sub-competencies described by Maa $\beta$ (2006) that are underlined in Table 1.

\section{The Mathematical Modeling Process}

In connection with assumptions and situation simplification, prospective teachers were generally able to recognize throughout the modeling process when assumptions were needed, but the level of proficiency they displayed varied as some of them stated assumptions that were more restrictive than needed. Assumptions and their critical role in developing a model were frequently discussed throughout the modeling module. As a result, all prospective teachers listed explicit assumptions and used them to create their models in their work on the Tree Leaf task. An interesting aspect of the findings is the purpose for the assumptions: some were made to simplify the situation while others were made to make the mathematics accessible. For example, assuming that oxygen is proportional to sun-exposed leaf area (Ahmed) simplifies the reality of the situation. On the other hand, Maribel's assumption mentioned earlier to use "for simplicity" a 
constant (average) rate in the equations is an assumption made to facilitate the mathematical computations.

All prospective teachers simplified the original situation in the task so we may conclude that all participants developed this sub-competency to some extent. However, there is no straightforward way to relate the extent of proficiency in simplifying the situation to the level of simplification (e.g. least or most simplified) since one expects different modelers to simplify a complex situation according to their expertise and experience (Borromeo Ferri 2006). Extreme levels of simplification leading to unrealistic (and possibly irrelevant) situations would indicate a need for improvement in this sub-competency but in our study; even the three models classified as "Most Simplified" maintained realistic features. On the other hand, we did not identify any prospective teacher's work in which the level of simplification of the problem was reduced iteratively. We conclude that the module was not sufficient for the participants to develop a simplification strategy in which they begin with a highly simplified reality and gradually make it more realistic.

The interdependence of assumption making, situation simplification and a mathematical model is evident in Bob's reflection where he expressed frustration about his inability to find a function that accounted for the leaf size since the time of budding, which he chose to include. This experience shows that the sub-competencies to make assumptions for the problem and simplify the situation and to mathematize relevant quantities and their relations are not independent. If the original situation is not sufficiently simplified, the resulting real model may be still too complex and additional simplifying assumptions may be required to formulate a model using mathematical concepts accessible to the modeler. 
The findings regarding interpretation of mathematical results in a context outside mathematics suggest a key factor that affects the way in which this sub-competency is displayed in the prospective teachers' work. The key factor is a mention of the implications that the conclusions drawn from the mathematical results have on the original situation. This is in contrast to an interpretation of the mathematical results as mere descriptions of what the variables in the expression represent in the original context, which we consider a lower level of proficiency. An example of a high level of proficiency in this sub-competency displayed by a prospective teacher is “... for each year the size of the leaves is decreasing, so it raises a question about whether the amount of oxygen being produced is significantly decreasing because of this. Although the size of the leaves is decreasing the sheer amount of these leaves is drastically increasing. So ... the tree does not need the leaves to be as large as in year 1" (Alejandro). This prospective teacher is interpreting the conflict between the product of a decreasing factor (the leaf size) and an increasing factor (the number of leaves) and its implication.

Maa $\beta$ (2006) lists the sub-competency to reflect on other ways of solving the problem or if solutions can be developed differently within the category of validating the solution, although this sub-competency is useful at any stage of the process. Our findings show that once the prospective teachers had finished the task, their thoughts on other approaches to solving the problem were mostly related to modifying the assumptions they made. This seems more consistent with a new iteration of their modeling process than with a different solution approach. However, after sharing their models during the poster presentations, most of the prospective teachers found value in being exposed to various mathematical approaches. Their reasons were related to emphasizing that mathematics is not always about a right or wrong way of solving a problem. 


\section{The Role of Mathematical Practices}

The prospective teachers' work on the Tree Leaf task showed evidence of the use of mathematical practices, which shows that mathematical modeling and mathematical practices are closely associated. Specifically, the practice most frequently reported in our study, Make sense of problems and persevere in solving them (Mathematical Practice 1) resonates with several modeling sub-competencies listed in Table 1. It is not surprising that the prospective teachers identified this practice since the iterative nature of mathematical modeling often means incremental improvement in each iteration. This requires perseverance and a constant evaluation of the results, especially when modeling is new to the prospective teachers. The use of the mathematical practice Use appropriate tools strategically by the prospective teachers was expected since the CCSSM's description of this practice mentions that when developing mathematical models, technology can enable students to "visualize the results of varying assumptions, explore consequences, and compare predictions with data" (CCSSI 2010, p. 7). Perhaps more surprising is the broad interpretation of what "tools" meant to the prospective teachers as a group, including technology (graphing calculators and software), mathematical representations (functions, graphs), and resources (textbooks with related problems, and prior mathematical knowledge). This thinking beyond physical tools points to the prospective teachers' resourcefulness.

\section{Productive Struggle: Frustration and Rewards}

The prospective teachers were familiar with word problems in which all pertinent information is given and the correct answer must be found, which is a very different scenario than a contextual situation in mathematical modeling. Realizing that the Tree Leaf task did not have a unique entry point and that they had to make choices to develop a viable approach, the 
prospective teachers in our study experienced cognitive dissonance, and expressed it as a feeling of frustration. As mentioned in the findings, they felt frustrated in the early stages of the process, unsure about making assumptions and how to account for the area of the leaves. Their frustration was acknowledged, and they were encouraged to identify simplifications and assumptions that would initiate the process of developing a model. This discussion prompted the prospective teachers to overcome the roadblock and move forward with the modeling process.

We viewed this experience as productive struggle. The prospective teachers' success in moving from frustration to an initial real model connects their productive struggle with the modeling sub-competency Make assumptions and simplify the situation, suggesting that productive struggle can help build competency in mathematical modeling. This type of example in combination with the prospective teachers' comments during their poster presentations demonstrated their developed knowledge about the modeling process as well as deeper mathematical thinking. For instance, they selected functions for their models based on features required for the approximations as opposed to a more traditional exercise of finding features of a given function. We posit that the prospective teachers in our study broadened and deepened their knowledge of mathematics and built competency in mathematical modeling,

\section{Teaching Mathematical Modeling}

Different solution approaches to the Tree Leaf task revealed a diverse use of interconnected mathematics concepts. There were also connections that the prospective teachers made between teaching and learning when discussing broadening the set of possible solution paths their future students might take to produce reasonable models to the same problem. Furthermore, the prospective teachers expressed that they would value student understanding of peers' work as well as communicating and critiquing the reasoning of others, which underscores 
the important role of the Mathematical Practices in their future teaching. The prospective teachers' plans to provide their future students opportunities to reason and think in mathematics reveals that they are not only thinking of their roles in teaching, but also taking into consideration the consequences of their teaching, that is, student learning.

Since many of the prospective teachers considered the Tree Leaf task difficult, it is understandable that they felt that it would be difficult for high school students. While the Tree Leaf task is aligned with many Common Core standards in the conceptual categories of Algebra, Functions and Modeling (CCSSI 2010, p.57), the prospective teachers' own high school experience did not emphasize modeling the way current standards demand. This may be why they expressed tension between the current intended mathematics curriculum and the curriculum they experienced as learners of mathematics or observed in the secondary classrooms.

The prospective teachers' reflections on assessment of the modeling tasks alluded to consideration of the process that students engage with in addition to the final product. They realized that placing value on the process allows for assessing of students' creativity, decisionmaking, initiative, and communication, thus giving a broader perspective of students' competencies in multiple areas of mathematics within modeling tasks. This finding is in alignment with the recommendations of the GAIMME report (Garfunkel \& Montgomery 2016), "Assessment should be in service of helping students improve their ability to model, which will, in time, translate to a better product" (p. 21).

\section{Limitations of the study}

A limitation of the study is that the instructor only witnessed the prospective teachers' work on the Tree Leaf task that was done during class periods, not the work done by them outside of class. The study relied on the prospective teachers' final reports, posters, 
presentations, and declarative reflections as data sources for this study. A more comprehensive data collection plan in which the instructor is able to track group thinking during all of the modeling work would produce deeper insights into the thinking process of the modeling cycle iterations. A richer set of data including individual interviews or videotape could have enhanced the findings. Future studies that include these data may be designed to provide further insights into effective ways of promoting the development of a larger set of modeling sub-competencies.

\section{Conclusions}

We have reported on a project designed to provide insight into the effectiveness of inserting a mathematical modeling module into an existing course to promote the development of modeling competency in prospective teachers who had no prior experience in mathematical modeling. The importance of the study stems from the fact that while mathematical modeling is part of the k-12 curriculum in the United States, many teachers have not received adequate preparation in this area. This state of affairs presents an opportunity to design effective ways of preparing teachers in mathematical modeling by adjusting current programs appropriately. Our approach was to implement within an existing course a module that provided an introduction to modeling and its main features, dedicated ample time to discussing and illustrating the importance of assumptions and multiple solution approaches in problem solving and in modeling specifically. The modeling tasks in the module required reflections on their solution process and on teaching and learning of mathematical modeling. The prospective teachers' work on the final activity of the module showed activation of several aspects of the four sub-competencies considered in the study. While the degree of coverage, or proficiency, in these sub-competencies is expected to increase with exposure to modeling and reflection on the process, the findings support the conclusion that the combination of activities in the module has been effective in 
translating mathematical modeling for prospective teachers from something unknown to recognizing modeling tasks, engaging in the required thinking for modeling, appreciating the benefits for student learning, and considering challenges for teaching mathematical modeling. These results inform the mathematics education research community and programs on fostering effective ways of preparing future secondary teachers in mathematical modeling.

The findings also point to ways of improving the module. Many of the prospective teachers' frustrations were related to finding an entry point for the task. The practice of highly simplifying the situation in order to get started with the explicit intent of revising the assumptions after gaining insight into the solution was not displayed in the data. This practice, common among mathematicians, should be emphasized in the module as it has the benefits of promoting an initial iteration of the process more readily, starting with a real model that is simple enough to mathematize, and potentially reducing the level of frustration experienced by the modeler.

\section{References}

Alexandra, R. N., Holbrook, M., \& Ewel, J. (2004). Developmental and physiological correlates of leaf size in Hyeronima alchorneoides (Euphorbiaceae). American Journal of Botany, 91(4), 582-589.

Anhalt, C. \& Cortez, R. (2016). Developing understanding of mathematical modeling in secondary teacher preparation. Journal of Mathematics Teacher Education, 19(6), 523545. doi: 10.1007/s10857-015-9309-8. http://link.springer.com/article/10.1007/s10857015-9309-8?wt_mc=alerts.TOCjournals 
Anhalt, C., Staats, S., Cortez, R., \& Civil, M (in press). Mathematical modeling and culturally relevant pedagogy. In Y. J. Dori, Z. Mevarech, \& D. Baker (Eds.), Cognition, metacognition, and culture in STEM education (pp. 174-195). Netherlands: Springer.

Association of Mathematics Teacher Educators. (2017). Standards for Preparing Teachers of Mathematics. Available online at amte.net/standards.

Bender, E. A. (2000). An Introduction to Mathematical Modeling. Mineola, New York: Dover Publishing Company. ISBN: 978-0486411804.

Blomhøj, M. \& Jensen, T. H. (2003). Developing mathematical modelling competence: Conceptual clarification and educational planning. Teaching Mathematics and its Applications, 22, 123-139.

Blum, W. \& Leiß, D. (2006). "Filling Up"-the problem of independence-preserving teacher interventions in lessons with demanding modelling tasks. In M. Bosch (Ed.), Proceedings of the Fourth Congress of the European Society for Research in Mathematics Education (pp. 1623-1633).

Blum, W. \& Niss, M. (1991). Applied mathematical problem solving, modeling, applications, and links to other subjects- state, trends and issues in mathematics instruction. Educational Studies in Mathematics, 22(1), 37-68.

Borromeo Ferri, R. (2006). Theoretical and empirical differentiations of phases in the modelling process. Zentralblatt für Didaktik der Mathematik, 38 (2), 86-95.

Conference Board of the Mathematical Sciences (2012). The Mathematical Education of Teachers II. Providence RI and Washington DC: American Mathematical Society and Mathematical Association of America. 
Common Core State Standards Initiative (2010), National Governors Association Center for Best Practices and Council of Chief State School Officers. http://www.corestandards.org/assets/CCSSI_Math\%20Standards.pdf

Doerr, H.M. (2007). What knowledge do teachers need for teaching mathematics through applications and modelling? In W. Blum, P.L. Galbraith, H-W. Henn and M.Niss (Eds.) Modelling and applications in mathematics education (pp. 69-78). New York: Springer.

Dym, C. (2004). Principles of Mathematical Modeling (Second Edition), Burlington, MA: Academic Press.

English, L. (2003). Mathematical modeling with young learners. In S. J. Lamon, W. A. Parker \& S. K. Houston (Eds.), Mathematical modelling: A way of life. ICTMA11 (pp. 3-7). Chichester: Horwood.

English, L. (2009). Promoting interdisciplinarity through mathematical modelling. ZDM Mathematics Education 41:161-181. DOI 10.1007/s11858-008-0106-z

Festinger, L. (1962). Cognitive dissonance. Scientific American, 207 (4): 93-107.

Frejd, P. (2014). Modes of mathematical modelling: An analysis of how modelling is used and interpreted in and out of school settings (Doctoral thesis, Linköping University, Linköping, Sweden). Retrieved from http://www.divaportal.org/smash/record.jsf?pid=diva2\%3A690259\&dswid=7047

Garfunkel, S. \& Montgomery, M. (2016) Guidelines for assessment and instruction in mathematical modeling education (GAIMME) report. Boston/Philadelphia: Consortium for Mathematics and Its Applications (COMAP)/Society for Industrial and Applied Mathematics (SIAM). 
Hiebert, J., \& Grouws, D. A. (2007). The effects of classroom mathematics teaching on students' learning. In F. K. Lester (Ed.), Second handbook of research on mathematics teaching and learning (pp. 371-404). Charlotte: Information Age.

Jensen, T. H. (2007). Assessing mathematical modelling competency. Mathematical Modeling (ICTMA 12): Education, Engineering and Economics, 141-148.

Kaiser, G. \& Brand, S. (2015). Modelling competencies: Past development and further perspectives. In G. A. Stillman, W. Blum \& M. S. Biembengut (Eds), Mathematical modelling in education research and practice: Cultural, social and cognitive influences, 129-149, Netherlands: Springer.

Kaiser, G., \& Schwarz, B. (2006). Mathematical modelling as bridge between school and university. ZDM Mathematics Education, 38(2), 196-208.

Kaiser, G., \& Stender, P. (2013). Complex modelling problems in co-operative, self-directed learning environments. In Teaching mathematical modelling: Connecting to research and practice (pp. 277-293). Netherlands: Springer.

Lesh, R., \& Doerr, H.M. (2003). In what ways does a models and modeling perspective move beyond constructivism? In R. Lesh \& H.M. Doerr (Eds.), Beyond constructivism: A models \& modeling perspective on mathematics problem solving, learning \& teaching, (pp. 383-403). Hillsdale, NJ: Lawrence Erlbaum Associates, Inc.

Lingefjärd, T. (2002). Mathematical modeling for preservice teachers: A problem from anesthesiology. International Journal of Computers for Mathematical Learning, 7(2), pp. 117-143.

Maaß, K. (2006). What are modeling competencies? Zentralblatt für Didaktik der Mathematik, $38(2), 113-142$. 
Meyer, D. (2015). Missing the promise of mathematical modeling. Mathematics Teacher 108(8), 578-83.

Mooney, D., \& Swift, R. (1999). A Course in Mathematical Modeling. Washington, DC: Mathematical Association of America.

National Council of Teachers of Mathematics (2000). Principles and Standards for School Mathematics. Reston, VA: Author.

National Council of Teachers of Mathematics (2014). Principles to Action: Ensuring Mathematical Success for All. Reston, VA: Author.

National Council of Teachers of Mathematics (2016). Mathematical Modeling and Modeling Mathematics, C. Hirsch \& A.R. McDuffie (Eds.), Annual Perspectives in Mathematics Education, Reston, VA: Author.

Ng, K.E.D. (2013).Teacher readiness in mathematical modelling: Are there differences between pre-service and in-service teachers? In G. A. Stillman, Kaiser G., Blum W., Brown J.P., (Eds.), Teaching mathematical modelling: Connecting to research and practice. International perspectives on the teaching and learning of mathematical modeling (pp.339-48). Springer: Dordrecht.

Niss, M., Blum, W., \& Galbraith, P. L. (2007). Introduction. In W. Blum, P. L. Galbraith, H. Henn, \& M. Niss (Eds.), Modelling and applications in mathematics education. The 14th ICMI study (pp. 3-32). New York: Springer.

Niss, M., \& Jensen, T. H. (Eds.). (2011). Competencies and mathematical learning-Ideas and inspiration for the development of mathematics teaching and learning in Denmark. English translation of parts I-VI of Niss and Jensen (2002). Tekster nr. 485. Roskilde University: IMFUFA. 
Olson, J. C., Colasanti, M. and Trujillo, K. (2006). Prompting growth for prospective teachers using cognitive dissonance. In Novotná, J., Moraová, H., Krátká, M. \& Stehlíková, N. (Eds.). Proceedings 30th conference of the International Group for the Psychology of Mathematics Education, Vol. 4, pp. 281-288. Prague: PME.

Siller, H-S. \& Kuntze, S. (2011). Modelling as a big idea in mathematics - knowledge and views of pre-service and in-service teachers. Journal of Mathematical Modelling and Application, 1(6), 33-39.

Stillman G., Brown J., Galbraith P. (2013) Identifying Challenges within Transition Phases of Mathematical Modeling Activities at Year 9. In R. Lesh, Galbraith P., Haines C., Hurford A. (Eds.) Modeling students' mathematical modeling competencies: International perspectives on the teaching and learning of mathematical modelling. pp. 385-398. Dordrecht: Springer. DOI10.1007/978-94-007-6271-8_33

Stillman, G., Kaiser, G., Blum, W., \& Brown, J. P. (2013). Teaching Mathematical Modelling: Connecting to Research and Practice: International Perspectives on the Teaching and Learning of Mathematical Modelling. Dordrecht: Springer. DOI10.1007/978-94-007$6540-5$

Strauss, A., \& Corbin, J. (1990). Basics of Qualitative Research: Grounded Theory Procedures and Techniques. Newbury Park, CA: Sage.

Soon, T. L. \& Cheng, A. K. (2013). Pre-service secondary school teachers' knowledge in mathematical modelling - A case study. In G. Stillman, Kaiser, G., Blum, W. \& Brown, J. P., (Eds.). Teaching mathematical modelling: connecting to research and practice: International perspectives on the teaching and learning of mathematical modelling. Dordrecht: Springer. DOI10.1007/978-94-007-6540-5 


\section{Tables}

\begin{tabular}{l} 
Table 1 \\
Sub-competencies of the modeling process listed by Maaß (2006). The underlined sub-competencies are \\
the focus of the current study. \\
\hline 1. Competencies to understand the real problem and to set up a model based on reality: \\
a. to make assumptions for the problem and simplify the situation; \\
b. to recognize quantities that influence the situation, to name them and to identify key variables; \\
c. to construct relations between the variables; \\
d. to look for available information and to differentiate between relevant and irrelevant information. \\
\hline 2. Competencies to set up a mathematical model from the real model: \\
a. to mathematize relevant quantities and their relations; \\
b. to simplify relevant quantities and their relations if necessary and to reduce their number and \\
c. to choose appropriate mathematical notations and to represent situations graphically. \\
3. Competencies to solve mathematical questions within this mathematical model. \\
a. to use heuristic strategies such as division of the problem into part problems, establishing \\
relations to similar or analog problems, rephrasing the problem, viewing the problem in a \\
b. to use mathematical knowledge to solve the problem. \\
4. Competencies to interpret mathematical results in a real situation: \\
a. to interpret mathematical results in extra-mathematical contexts; \\
b. to generalize solutions that were developed for a special situation; \\
c. to view solutions to a problem by using appropriate mathematical language and/or to \\
communicate about the solutions. \\
5. Competencies to validate the solution: \\
a. to critically check and reflect on found solutions; \\
b. to review some parts of the model or again go through the modelling process if solutions do not \\
c. to reflect on other ways of solving the problem or if solutions can be developed differently; \\
d. to generally question the model (Blum \& Kaiser 1997, p.9). \\
\hline
\end{tabular}

\begin{tabular}{|c|c|c|c|c|c|c|c|c|c|c|c|}
\hline $\begin{array}{l}\text { Table } 2 \\
\text { Comparison }\end{array}$ & The & af Len & $h A_{l}$ & oxime & 证 & en by & lode & And & & & \\
\hline $\mathrm{t}$ (year) & 1 & 2 & 3 & 4 & 5 & 6 & 7 & 8 & 9 & 10 & 11 \\
\hline $\begin{array}{l}L(\mathrm{t}), \text { Model } \\
\text { A }\end{array}$ & 45 & $\begin{array}{l}35.6 \\
3\end{array}$ & 29 & $\begin{array}{l}24.3 \\
1\end{array}$ & 21 & $\begin{array}{l}18.6 \\
6\end{array}$ & 17 & $\begin{array}{l}15.8 \\
3\end{array}$ & 15 & $\begin{array}{l}14.4 \\
1\end{array}$ & 14 \\
\hline$L(\mathrm{t})$, Model & 45. & 33.1 & 27. & 24.2 & 21. & 20.2 & 18. & 17.7 & 16. & 16.0 & 15. \\
\hline
\end{tabular}




\begin{tabular}{|l|l|l|l|l|l|l|l|l|l|l|l|}
\hline $\mathrm{B}$ & $\mathbf{2}$ & & $\mathbf{6}$ & & 9 & & 8 & & 8 & & $\mathbf{3}$ \\
\hline
\end{tabular}

\section{Figures}

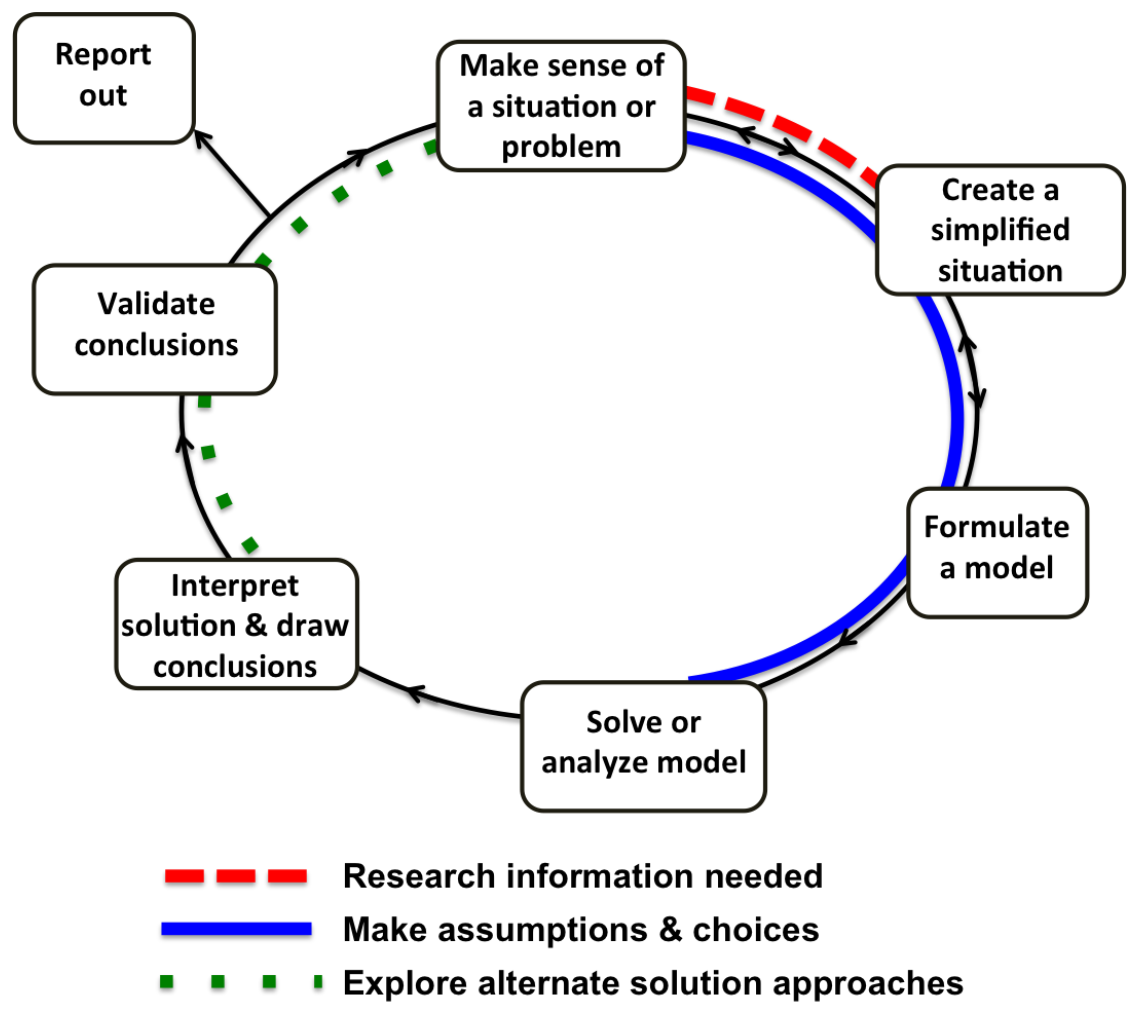

Figure 1. A representation of the mathematical modeling process. 


\section{The Tree Leaf Modeling Task: Photosynthesis}

You might remember that during photosynthesis, the leaves of plants and trees capture the energy of sunlight and transform it to produce sugar and release oxygen into the air. Photosynthesis is critically important because that oxygen that is released is crucial to our lives. Plants absorb the light through the leaves that are exposed to the sun, so the size of the leaves and the number of leaves are important factors in the release of oxygen during photosynthesis. Some young trees have larger leaves than older trees. For example, the Suradan Hardwood tree, called Hyeronima alchorneoides, has smaller leaves when the trees are older. The figure below shows the shape and size of typical leaves of the Suradan Hardwood from 1-year-old, 3-year-old, 11-year-old, and 30-yearold trees (left to right). Notice that the leaves get smaller as the trees get older.

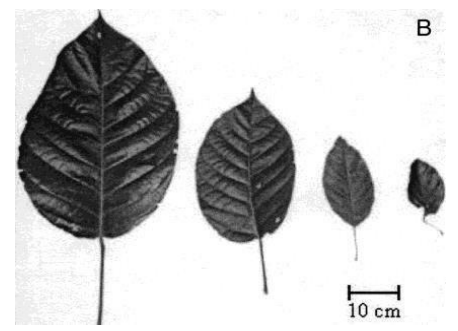

Pictures of leaves from the Suradan Hardwood tree. The pictures from left to right are from a 1year-old tree, a 3-year-old tree, an 11-year-old tree, and finally a tree that is more than 30 years old.

The length of the leaves, which is measured from the bottom to the tip of the leaf along the centerline, has been measured and collected in the figure below. The data at the top correspond to 1-year-old trees. The data in the middle correspond to 3-year-old trees, and the data at the bottom correspond to 11-year-old trees.

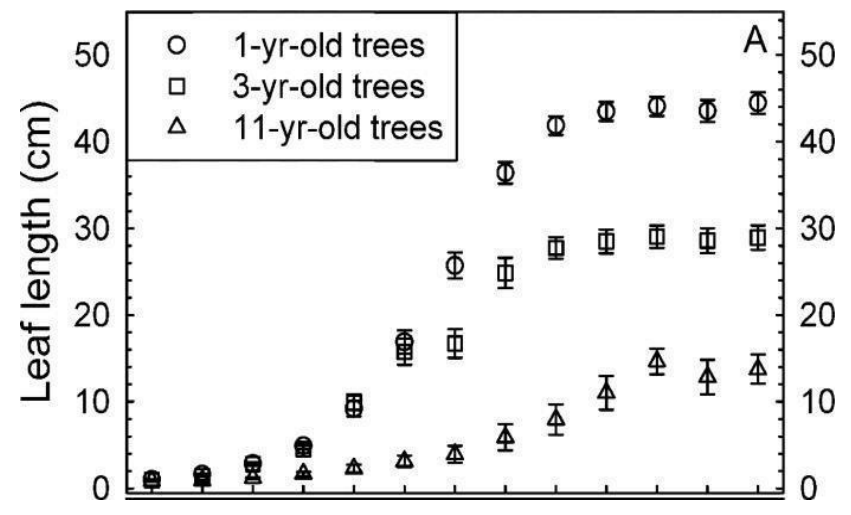

Measurements of the average size of leaves from the Suradan Hardwood tree. The leaves grow from a bud (at day zero) to a maximum size after about 73 days. The top data is for 1 -year-old trees; the middle data correspond to 3-year-old trees; and the bottom data correspond to 11-yearold trees.

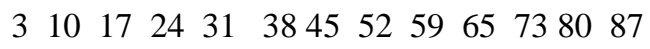

\section{Days since budding}

The goal of this project is to use the data provided in these figures to understand the ability of the trees to produce oxygen during photosynthesis as the trees get older and their leaves get smaller. Since the data provided is only for years 1, 3 and 11, your model should be used to predict the average size of the leaves for trees that are 4-10 years old (the years that we do not have data for) and to draw conclusions about the ability of the trees to release oxygen in later years in comparison with year 1 .

Figure 2. The Tree Leaf modeling task. 


\begin{tabular}{|l|l|}
\hline \multicolumn{1}{|c|}{ Prospective Teachers' Interpretation of Results } & \multicolumn{1}{c|}{$\begin{array}{c}\text { Contextualization Proficiency } \\
\text { Level. Reason }\end{array}$} \\
\hline $\begin{array}{l}\text { The average leaf size, under the proposed assumptions, tells us the } \\
\text { average surface area of the leaves of a tree. Multiplying this average by } \\
\text { the estimated number of leaves on a tree, } \mathrm{n} \text {, will give us an estimate of } \\
\text { the total surface area that allows for photosynthesis. This allows us to } \\
\text { draw conclusions about the amount of oxygen a tree produces. } \\
\begin{array}{l}\text { Supposing oxygen is released at a constant rate, } \mathrm{k} \text {, whose unites are in } \\
\mathrm{mL} \text { per } \mathrm{cm}^{2} \text { per hour, we can estimate the amount of oxygen created by } \\
\text { the expression } \mathrm{k} \cdot \mathrm{A}(\mathrm{y}) \cdot \mathrm{n} \text {. (David) }\end{array}\end{array}$ & $\begin{array}{l}\text { Low. It is a description of the model } \\
\text { equation; little connection to context } \\
\text { and no implications. }\end{array}$ \\
\hline $\begin{array}{l}\text { Since the equation gives the rate of oxygen production, the amount of } \\
\text { oxygen produced is the integral of this function. Since this function is } \\
\text { never negative, we have that the oxygen production is always positive } \\
\text { and increasing... (Jesus) }\end{array}$ & $\begin{array}{l}\text { High. Contextualizes and gives } \\
\text { implication. }\end{array}$ \\
\hline Figure 3. Examples of coding of contextualization. & \\
\hline
\end{tabular}

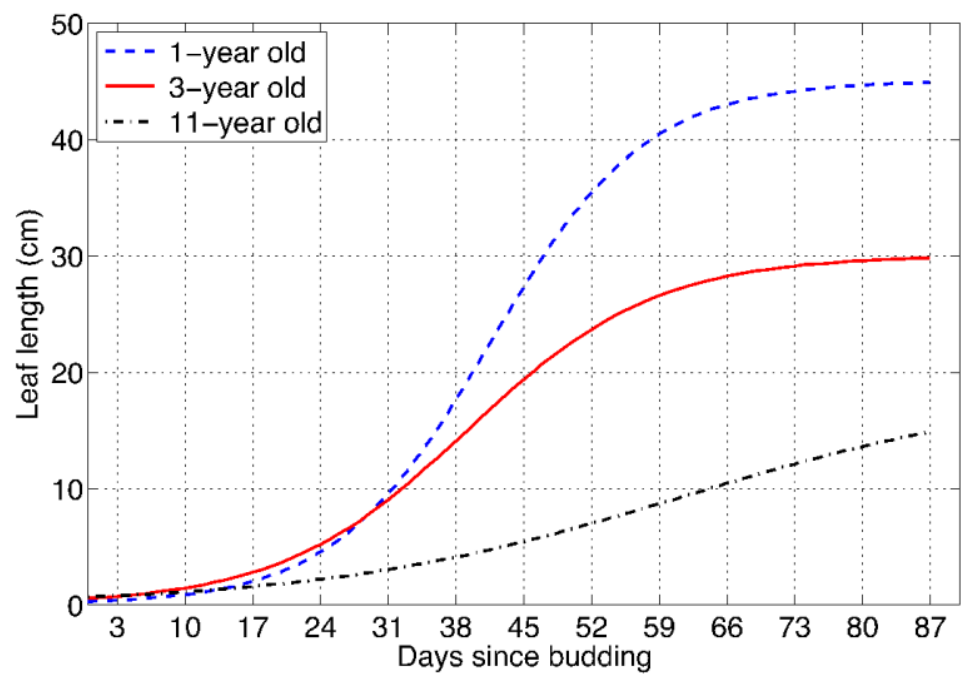

Figure 4. Plot of logistic functions described in Model C. 